\title{
Model Test Study on Dynamic Response of Expressway Plastic- Reinforced Earth Embankment under Earthquake
}

\author{
Xue Han $\mathbb{D}^{1}$, Pengyue Ji, ${ }^{2}$ Qichen $\mathrm{Gu}^{2}$ and Guangsen $\mathrm{Mu}^{2}$ \\ ${ }^{1}$ School of Civil \&Architectural Engineering, Hunan University of Arts and Science, Changde 415000, China \\ ${ }^{2}$ School of Architectural Engineering, Heilongjiang University of Science \& Technology, Harbin 150022, China \\ Correspondence should be addressed to Xue Han; hanxue69@163.com
}

Received 10 January 2021; Revised 7 February 2021; Accepted 11 February 2021; Published 25 February 2021

Academic Editor: Yu Wang

Copyright ( $) 2021$ Han Xue et al. This is an open access article distributed under the Creative Commons Attribution License, which permits unrestricted use, distribution, and reproduction in any medium, provided the original work is properly cited.

\begin{abstract}
Aiming at the seismic response of plastic geogrid-reinforced embankments, with Zhounan Expressway as the research engineering background, a self-designed seismic-rainfall coupled slope model test system was designed and used to produce $1: 20$ scale plastic geogrid-reinforced embankments. Moreover, the physical model of the unreinforced embankment under Hanshin wave, Wenchuan wave, Tianjin wave, etc. was also studied to carry out comparative analysis on seismic response and dynamic response on test model. The dynamic characteristics and dynamic response of the embankment model were tested from low to high seismic intensity; the changes of the embankment's natural frequency, damping ratio, acceleration at the measuring point, and dynamic earth pressure were analyzed; and the main influencing factors and damage to the embankment seismic response feature were discussed herein. The test results showed that the initial natural frequency of the reinforced embankment was $42.4 \%$ higher than that of the unreinforced embankment, and its initial damping ratio reduced by $19.4 \%$. The attenuation effect of the natural frequency and damping ratio of the reinforced embankment with the loading history was significantly lower than that of the unreinforced embankment. Embankment reinforcement exhibited a very good inhibitory effect on the PGA amplification effect of the embankment, and the inhibitory effect on the interior of the slope was more significant than that on the slope. Moreover, the type of seismic wave, the amplitude of the seismic wave, and the frequency of the seismic wave significantly influenced the PGA amplification effect of the embankment. The peak dynamic soil pressure of the unreinforced embankment at the same location was significantly greater than that of the reinforced embankment. The two embankment models showed significantly different antivibration damage performance. After the peak acceleration of $2 \mathrm{~m} \mathrm{~s}^{-2}$ was loaded, no cracks were seen on the surface of the embankment model. When the peak acceleration of $3 \mathrm{~m} \mathrm{~s}^{-2}$ was loaded, on the slopes of the two embankment models, smaller cracks were observed in the middle and upper parts of the face. When the peak acceleration of $4 \mathrm{~m} \mathrm{~s}^{-2}$ was loaded, the failure of the unreinforced embankment model was obvious. Large cracks on the top of the slope could reach $16 \mathrm{~mm}$ in width, and $27 \mathrm{~mm}$ settlement appeared at the top, and the slope was convex. The reinforced embankment model was only on the slope shoulder. Moreover, there were fine cracks on the top, and the slope top settlement was less than $5 \mathrm{~mm}$. The research results provide theoretical support for preventing and controlling the road embankment vibration diseases and improving highway durability design.
\end{abstract}

\section{Introduction}

China is located between the Pacific Rim seismic belt and the Himalayan-Mediterranean seismic belt. Since the $20^{\text {th }}$ century, strong earthquakes have occurred in China and the frequency of earthquakes has been increasing year by year [1]. There are frequent reports on structural damage to highway subgrades during previous earthquakes. Moreover, subgrade subsidence, cracking, distortion, and slippage occur fre- quently. The dynamic response characteristics of subgrades under earthquakes have an important impact on highway safety and durability.

Reinforced embankments have gradually been widely used in engineering practice. Reinforcement can limit the lateral deformation of the embankment to a certain extent, disperse the additional load and settlement of the embankment, inhibit the transmission of seismic loads, and finally improve the seismic resistance of expressways to varying degrees [2- 
4]. Extensive research attention has been paid to the investigation of the dynamic response and seismic performance of reinforced soil slopes. Although there are few researches directly highlighting the dynamic problems of reinforced embankment slopes, numerous research reports are available on the study of reinforced slopes and retaining walls under earthquake action. For instance, Jianzhou et al. [5] used PLAXIS software numerical calculation method to study the dynamic characteristics of double-sided reinforced embankments under earthquake action and analyzed the maximum stress distribution of each layer of the embankment and the settlement form of the embankment. Lesniewska [6] used RES analysis software and the rigid-plastic theory of reinforced soil to analyze the differential boundary value of the bearing capacity of reinforced and unreinforced soil embankment slopes. Halder et al. [7] combined the lower bound finite element limit analysis method, anisotropic random field modeling method, and Monte Carlo simulation analysis to calculate the bearing capacity of the cohesive soil-reinforced embankment slope. Nouri et al. [8] used the limit equilibrium horizontal slice method to evaluate the pseudostatic acceleration and amplification effect of reinforced soil slopes and retaining walls. Furthermore, Lin et al. [9] compared the ground motion response of an unreinforced slope with that of a reinforced slope and found that the vertical acceleration magnification rate of the reinforced embankment slope was much smaller than that of the unreinforced embankment slope. Lihua et al. [10] conducted shaking table model experiments to study the dynamic response performance of unreinforced slope, waste tire strings and three-way geogrid composite reinforced slope, and tire strings and tire fragment composite-reinforced embankment slopes under earthquake action. The acceleration responses of the embankment slope model along the slope height distribution law under different seismic waves, acceleration peaks, and reinforcement methods were discussed. Hongwei et al. [11] carried out shaking table model tests for investigating the seismic performance of geobagreinforced soil retaining walls under earthquake action. $\mathrm{Lu}$ [12] conducted a shaking table test on composite Gabion geogrid-reinforced soil retaining wall model with different similarity ratios, describing the macroscopic phenomenon of the test model under earthquake action, and they further studied the model retaining wall under earthquake action. Using the dynamic response, they tested the acceleration response and magnification of the backfill and tested the frequency spectrum characteristics at different heights of the model, the horizontal displacement of the wall, and the vertical settlement of the fill and finally compared and analyzed the parameters given in the design code. Jiang et al. [13] developed a combined panel reinforced soil retaining wall and conducted on-site filling tests and indoor shaking table model tests. Srilatha et al. [14] studied the influence of the fundamental vibration frequency on the dynamic response of unreinforced and reinforced soil slopes through shaking table tests and found that the acceleration and displacement responses of slopes with different reinforcement numbers and positions did not increase with frequency and linear growth. Bahadori et al. [15] conducted a shaking table test study on the liquefaction problem of the liquefiable soil layer reinforced with geogrid and geocomposite and found that the antiliquefaction settlement performance of geocomposite reinforcement was significantly better than that of geogrid reinforcement. Panah et al. [16] conducted a series of $1 \mathrm{~g}$ shaking table tests on the $80 \mathrm{~cm}$ high reinforced soil retaining wall model and studied the effect of the length, distribution, and shape (sawtooth and parallel) of the steel bar on the failure mode of the retaining wall. Furthermore, displacement and acceleration magnification factor has also been studied. Wartman et al. [17] analyzed the mechanism of permanent displacement of the slope under the action of seismic load and commented on the Newmark slider displacement calculation method. Koseki et al. [18] analyzed the seismic performance and potential failure mechanism of reinforced earth retaining walls. Edinçliler et al. [19] used the shaking table test method to study the seismic performance of slag as a filler for reinforced soil retaining walls.

Plastic reinforced soil embankments are widely used in engineering practice. Although scientific and technological researchers have carried out certain research work on the seismic effects of reinforced soil slopes, the seismic effects of plastic geogrid-reinforced embankments have rarely been investigated [20-25]. The current seismic design of highways nor does the code evaluate the seismic performance of plastic-reinforced embankments. In-depth study of the dynamic response of plastic-reinforced embankment under earthquake action and its failure characteristics was used to qualitatively and quantitatively analyze the seismic performance and reinforcement effect of plastic-reinforced embankment. This study provides important theories and engineering design/guidelines for preventing and treating earthquake-induced damage and destruction of embankment.

\section{Model Test Design}

2.1. Model Test System. In this study, a self-designed and customized seismic action slope model test system (see Figure 1), including hydraulic servo power loading system, shaking table, model box, control system, data acquisition, and analysis and processing system, was adopted to perform the tests. The dimension of the slope model box was $2 \mathrm{~m} \times 1.5 \mathrm{~m} \times$ $1.8 \mathrm{~m}$, which can be used for various earthquake-induced slope scale model tests.

2.2. Engineering Background. The embankment model test considered the No. 8 section of Zhounan Expressway as the research engineering background, and the pile number section was $\mathrm{K} 18+000-\mathrm{K} 42+600$ and $\mathrm{K} 42+600-\mathrm{K} 54+100$. The upper part of the strata is dominated by Quaternary Holocene alluvial silt clay and silt soil, with some interbedded sand layers, and the upper part of the silty clay is soft plasticplastic; and the lower part is an interbedded silty clay and silt soil. The sand layer is plastic-hard plastic. The earthquake fortification intensity is $7^{\circ}$. This is a section with a large embankment filling height, the maximum filling height of $10 \mathrm{~m}$, the soil cohesion of the foundation bearing layer $c=$ $19.82 \mathrm{KPa}$, the internal friction angle $\varphi=27^{\circ}$, the natural 


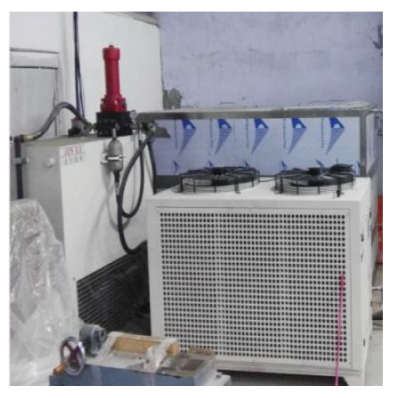

(a) Hydraulic power system

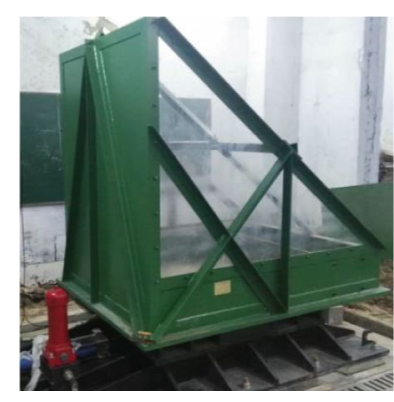

(b) Test model box

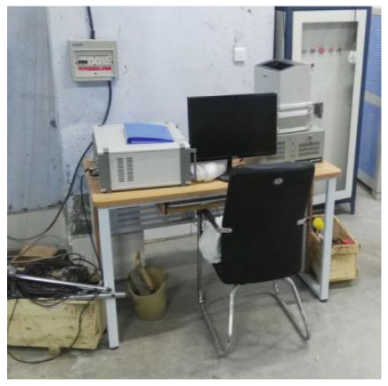

(c) Countertop

Figure 1: Earthquake physical model test system for slope.

density of $2074 \mathrm{~kg} \mathrm{~m}^{-3}$, and the embankment earth pressure. The actual control dry density is $1790 \mathrm{~kg} \mathrm{~m}^{-3}$, the cohesion force $c=11.31 \mathrm{KPa}$, and the internal friction angle $\varphi=24^{\circ}$.

2.3. Design and Production of Test Model. The embankment model design and the layout of the main measuring points are shown in Figure 2. Two types of embankment models were constructed: one was a filled embankment without reinforcement measures, and the other was a plastic-reinforced embankment. Owing to the symmetry of the cross section of the embankment, the two embankment models were designed in half width, and the geometric similarity ratio $\mathrm{Cl}$ was designed to be 20 . Therefore, the total height of the prototype embankment after being scaled down was $800 \mathrm{~mm}$, the cross-sectional direction of the foundation was $2000 \mathrm{~mm}$, the thickness range was designed to be $300 \mathrm{~mm}$, the height of the filled embankment was $500 \mathrm{~mm}$, and the top cross-sectional dimension was $675 \mathrm{~mm}$. The size of the foundation and the embankment along the road was $1500 \mathrm{~mm}$ according to the model box size. The slope angle of the embankment was the same as that of the prototype; using a broken line grading, the upper part was grading $1: 1.5$; and the lower part was grading $1: 1.75$. The ingredients and filling methods of the two embankment models were completely the same. The plastic reinforcement laying method of the reinforced embankment was horizontal through long bars, and the vertical spacing was $100 \mathrm{~mm}$.

The model similarity design takes the embankment geometry size and packing density as the basic control quantities and determines the similarity relationship of other physical parameters of the embankment according to the Buckingham theorem to calculate the similarity law of the embankment model. The physical model test similarity design is presented in Table 1.
After the embankment model was designed, the soil was sieved to remove oversized, layered, and compacted particles. The foundation soil was evenly filled and compacted in six layers, the filled embankment was evenly filled and compacted in five layers, and the plastic geogrid was spread between each layer of the reinforced embankment model. Each layer of soil was compacted to control the dry density of $1790 \mathrm{~kg} \mathrm{~m}^{-3}$. Corresponding sensors were embedded in the model making project based on the designed measuring points. The completed embankment model entities are shown in Figure 3.

\section{Seismic Wave Selection and Test Loading System}

Three typical seismic wave types, namely, Hanshin wave (code-named KOB) Figure 4, Wenchuan wave (code-named WC) Figure 5, and Tianjin wave (code-named TJ) Figure 6, were used for test loading. The peak acceleration of various waves was controlled to be at $0.5,1,2,3$, and $4 \mathrm{~m} \mathrm{~s}^{-2}$ fivelevel loading, and various waves were processed with four types of time compression ratios. The peak acceleration of white noise (code named WTN) was controlled to be at $0.3 \mathrm{~m} \mathrm{~s}^{-2}$, as shown in Figure 7, to measure the initial dynamic characteristics of the model and its changes during the loading process. The loading of various seismic waves was carried out interspersed by magnitude, and the specific loading system is presented in Table 2 .

\section{Test Results and Analysis}

Comparative analysis of the dynamic characteristics was carried out. Dynamic response and influencing factors of reinforced and unreinforced embankment models were studied, 


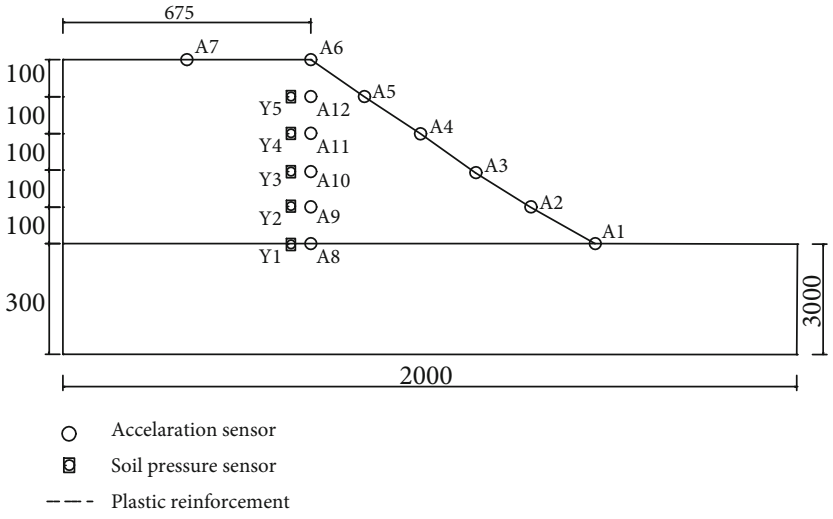

(a) Unreinforced embankment model design



(b) Reinforced embankment model design

Figure 2: Embankment model and the layout of measuring points.

TABLE 1: Embankment physical model test similarity ratio summary.

\begin{tabular}{lccc}
\hline Physical and mechanical parameters & Law of similarity & Similarity ratio (simplified) & Remarks \\
\hline Geometric size $l$ & $C_{1}$ & $C_{l}$ & Control amount \\
Acceleration $a$ & $C_{a}=1$ & 1 & Utilization of prototype materials \\
Packing density $\rho$ & $C_{\rho}$ & 1 & Utilization of prototype materials \\
Internal friction angle $\varphi$ & $C_{\varphi}=1$ & 1 & Utilization of prototype materials \\
Cohesion $c$ & $C_{c}=C_{\rho} C_{l}$ & $C_{l}$ & - \\
Dimensionless coefficient $K$ & $C_{K}$ & 1 & Utilization of prototype materials \\
Stress $\sigma$ & $C_{\sigma}=C_{\rho} C_{l}$ & $C_{l}$ & - \\
Strain $\varepsilon$ & $C_{\varepsilon}=C_{K}{ }^{-1} C_{\rho}{ }^{1 / 2} C_{l}{ }^{1 / 2}$ & $C_{l}{ }^{1 / 2}$ & - \\
Displacement $u$ & $C_{u}=C_{K}{ }^{-1} C_{\rho}{ }^{1 / 2} C_{l}^{3 / 2}$ & $C_{l}^{3 / 2}$ & Introduced in postprocessing similarity ratio \\
Speed $v$ & $C_{v}=C_{K}{ }^{-1 / 2} C_{\rho}{ }^{1 / 4} C_{l}^{3 / 4}$ & $C_{l}^{3 / 4}$ & Introduced in postprocessing similarity ratio \\
Time $t$ & $C_{t}=C_{K}{ }^{-1 / 2} C_{\rho}{ }^{1 / 4} C_{l}^{3 / 4}$ & $C_{l}^{3 / 4}$ & Scaling by time similarity \\
\hline
\end{tabular}

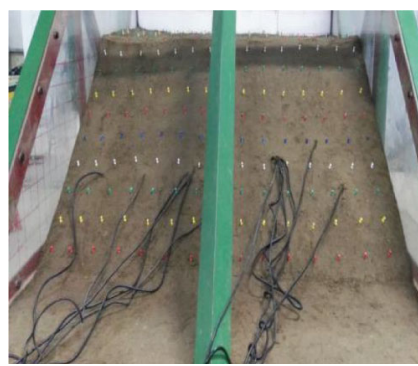

(a) Unreinforced embankment model

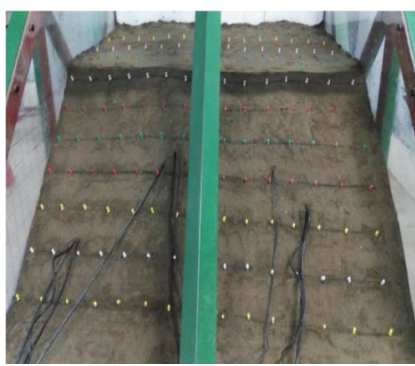

(b) Reinforced embankment model

Figure 3: Physical embankment model.

and the failure characteristics of the two embankment models were investigated.

4.1. Dynamic Characteristics of Embankment Model. The natural frequency and damping ratio are the main dynamic characteristic parameters of the embankment model. Before seismic waves were loaded in each working condition, the embankment model was tested with white noise with an amplitude of $0.3 \mathrm{~m} \mathrm{~s}^{-2}$, and the white noise transfer function of each measurement point was identified. Moreover, the average value of the identified natural frequency and damping ratio was taken as the characteristic natural frequency and damping ratio of the embankment model. The curves highlighting the variation in the natural frequency and 


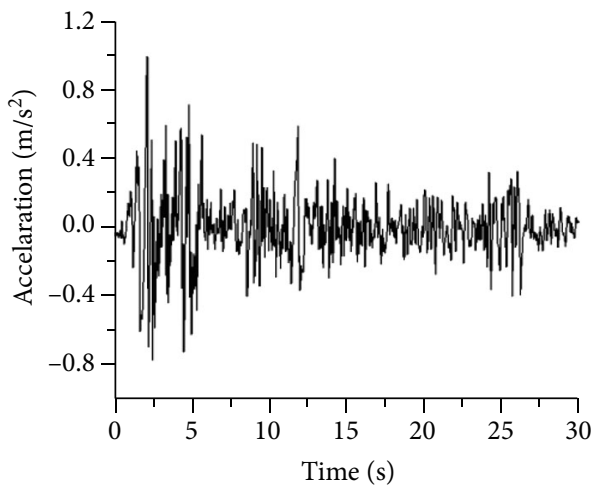

FIGURE 4: KOB wave acceleration time history curve.

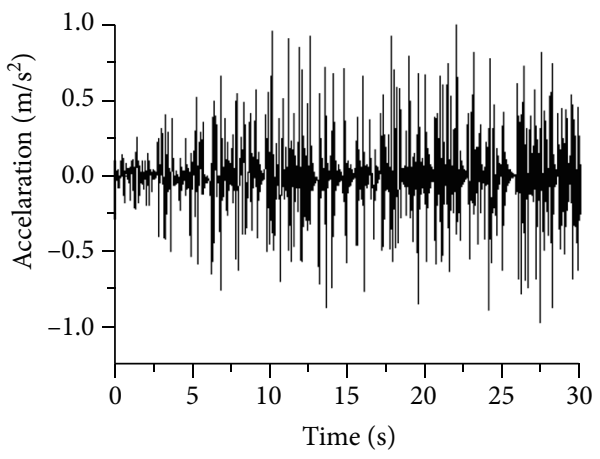

FiguRE 5: WC wave acceleration time history curve.

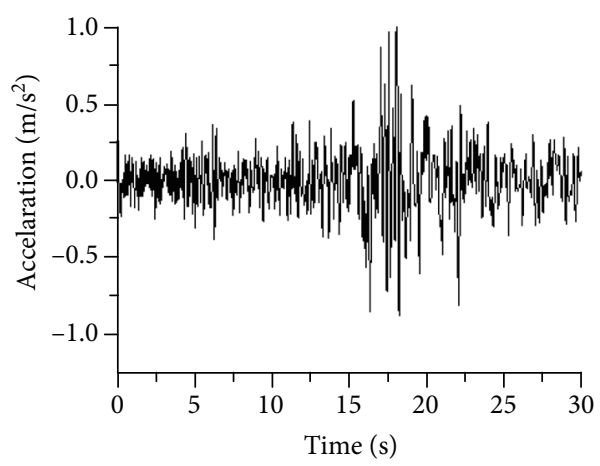

FIgURE 6: Wave acceleration time history curve.

damping ratio of the two embankment models with the loading history are shown in Figure 8.

Figure 8(a) demonstrates that the natural frequencies of the two embankment models gradually decrease with the loading process. The initial natural frequency of the unreinforced embankment is $12.63 \mathrm{~Hz}$, until the seismic wave test conditions are loaded, and then its natural frequency is reduced to $9.23 \mathrm{~Hz}$, corresponding to a drop of $26.9 \%$. When the initial natural frequency of the reinforced embankment is $17.98 \mathrm{~Hz}$, the load is completed. The frequency is reduced to $13.74 \mathrm{~Hz}$, corresponding to a drop of $23.6 \%$. Figure 8(b) illustrates that the damping ratio of the two embankment models gradually increases with the loading history. The initial

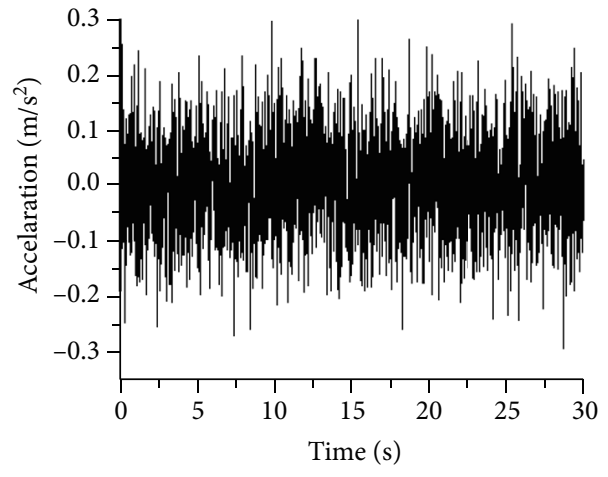

FIGURE 7: White noise acceleration time history.

damping ratio of the unreinforced embankment was 0.098 , and the damping ratio increased to 0.146; an increase of $49.4 \%$ after the seismic wave test conditions was loaded. The initial damping ratio of the reinforced embankment was 0.079 , and the damping ratio increased to 0.106 after the loading was completed. This corresponded to an increase of $37.3 \%$. The test data showed that reinforcement could effectively improve the dynamic characteristics of the embankment. The initial natural frequency of the reinforced embankment was $42.4 \%$ higher than that of the unreinforced embankment, and its initial damping was reduced by $19.4 \%$ compared to the unreinforced embankment. After the multicondition loading process, the natural frequency decreased and the increase of damping ratio of the reinforced embankment model was smaller than those of the unreinforced embankment, Moreover, the dynamic damage resistance of the reinforced embankment was significantly better than that of the unreinforced embankment.

4.2. Dynamic Response of Embankment Model. The PGA amplification effect and dynamic earth pressure of the measuring points under different loading conditions were used as the main observation indexes of the dynamic response, and the analysis is presented in the subsequent sections.

\subsubsection{Analysis of PGA Amplification Effect at Measuring} Point. The PGA amplification factor of the measuring point was calculated according to the peak acceleration data of the measuring point in each working condition, that is, the ratio of the peak acceleration of each measuring point to the measured peak acceleration of the table. After comparing the data of multiple working conditions, the PGA amplification coefficients of the three seismic wave action measuring points exhibited similar characteristics. Herein, the KOB-18 and KOB-5 working conditions were used for analysis. The PGA amplification coefficients of the two embankment model measuring points were along the height. The change rule is shown in Figures 9 and 10.

The figure shows that from bottom to top along the height of the embankment, the PGA amplification coefficients of the slope measurement points of the two embankment models show an overall increasing trend, with the maximum value appearing at the top of the slope. The PGA amplification coefficients of the reinforced embankment at 
TABLE 2: Embankment physical model test loading system.

\begin{tabular}{|c|c|c|c|c|c|c|}
\hline Test number & Case code & Peak acceleration $\left(\mathrm{m} \mathrm{s}^{-2}\right)$ & Time compression ratio & Test number & Case code & White noise peak $\left(\mathrm{m} \mathrm{s}^{-2}\right)$ \\
\hline & & & & 1 & WTN-1 & 0.3 \\
\hline 2 & KOB-1 & 0.5 & 9.457 & 3 & WTN-2 & 0.3 \\
\hline 4 & WC-1 & 0.5 & 9.457 & 5 & WTN-3 & 0.3 \\
\hline 6 & TJ-1 & 0.5 & 9.457 & 7 & WTN-4 & 0.3 \\
\hline 8 & KOB-2 & 0.5 & 4.472 & 9 & WTN-5 & 0.3 \\
\hline 10 & WC-2 & 0.5 & 4.472 & 11 & WTN-6 & 0.3 \\
\hline 12 & $\mathrm{TJ}-2$ & 0.5 & 4.472 & 13 & WTN-7 & 0.3 \\
\hline 14 & KOB-3 & 0.5 & 2.115 & 15 & WTN-8 & 0.3 \\
\hline 16 & WC-3 & 0.5 & 2.115 & 17 & WTN-9 & 0.3 \\
\hline 18 & $\mathrm{TJ}-3$ & 0.5 & 2.115 & 19 & WTN-10 & 0.3 \\
\hline 20 & KOB-4 & 0.5 & 1 & 21 & WTN-11 & 0.3 \\
\hline 22 & WC-4 & 0.5 & 1 & 23 & WTN-12 & 0.3 \\
\hline 24 & $\mathrm{TJ}-4$ & 0.5 & 1 & 25 & WTN-13 & 0.3 \\
\hline 26 & KOB-5 & 1 & 9.457 & 27 & WTN-14 & 0.3 \\
\hline 28 & WC-5 & 1 & 9.457 & 29 & WTN-15 & 0.3 \\
\hline 30 & TJ-5 & 1 & 9.457 & 31 & WTN-16 & 0.3 \\
\hline 32 & KOB-6 & 1 & 4.472 & 33 & WTN-17 & 0.3 \\
\hline 34 & WC-6 & 1 & 4.472 & 35 & WTN-18 & 0.3 \\
\hline 36 & TJ-6 & 1 & 4.472 & 37 & WTN-19 & 0.3 \\
\hline 38 & KOB-7 & 1 & 2.115 & 39 & WTN-20 & 0.3 \\
\hline 40 & WC-7 & 1 & 2.115 & 41 & WTN-21 & 0.3 \\
\hline 42 & TJ-7 & 1 & 2.115 & 43 & WTN-22 & 0.3 \\
\hline 44 & KOB-8 & 1 & 1 & 45 & WTN-23 & 0.3 \\
\hline 46 & WC-8 & 1 & 1 & 47 & WTN-24 & 0.3 \\
\hline 48 & TJ-8 & 1 & 1 & 49 & WTN-25 & 0.3 \\
\hline 50 & KOB-9 & 2 & 9.457 & 51 & WTN-26 & 0.3 \\
\hline 52 & WC-9 & 2 & 9.457 & 53 & WTN-27 & 0.3 \\
\hline 54 & TJ-9 & 2 & 9.457 & 55 & WTN-28 & 0.3 \\
\hline 56 & KOB-10 & 2 & 4.472 & 57 & WTN-29 & 0.3 \\
\hline 58 & WC-10 & 2 & 4.472 & 59 & WTN-30 & 0.3 \\
\hline 60 & TJ-10 & 2 & 4.472 & 61 & WTN-31 & 0.3 \\
\hline 62 & KOB-11 & 2 & 2.115 & 63 & WTN-32 & 0.3 \\
\hline 64 & WC-11 & 2 & 2.115 & 65 & WTN-33 & 0.3 \\
\hline 66 & TJ-11 & 2 & 2.115 & 67 & WTN-34 & 0.3 \\
\hline 68 & KOB-12 & 2 & 1 & 69 & WTN-35 & 0.3 \\
\hline 70 & WC-12 & 2 & 1 & 71 & WTN-36 & 0.3 \\
\hline 72 & $\mathrm{TJ}-12$ & 2 & 1 & 73 & WTN-37 & 0.3 \\
\hline 74 & KOB-13 & 3 & 9.457 & 75 & WTN-38 & 0.3 \\
\hline 76 & WC-13 & 3 & 9.457 & 77 & WTN-39 & 0.3 \\
\hline 78 & $\mathrm{TJ}-13$ & 3 & 9.457 & 79 & WTN-40 & 0.3 \\
\hline 80 & KOB-14 & 3 & 4.472 & 81 & WTN-41 & 0.3 \\
\hline 82 & WC-14 & 3 & 4.472 & 83 & WTN-42 & 0.3 \\
\hline 84 & TJ-14 & 3 & 4.472 & 85 & WTN-43 & 0.3 \\
\hline 86 & KOB-15 & 3 & 2.115 & 87 & WTN-44 & 0.3 \\
\hline 88 & WC-15 & 3 & 2.115 & 89 & WTN-45 & 0.3 \\
\hline 90 & TJ-15 & 3 & 2.115 & 91 & WTN-46 & 0.3 \\
\hline 92 & KOB-16 & 3 & 1 & 93 & WTN-47 & 0.3 \\
\hline 94 & WC-16 & 3 & 1 & 95 & WTN-48 & 0.3 \\
\hline
\end{tabular}


TABLE 2: Continued.

\begin{tabular}{lcccccc}
\hline Test number & Case code & Peak acceleration $\left(\mathrm{m} \mathrm{s}^{-2}\right)$ & Time compression ratio & Test number & Case code & White noise peak $\left(\mathrm{m} \mathrm{s}^{-2}\right)$ \\
\hline 96 & TJ-16 & 3 & 1 & 97 & WTN-49 & 0.3 \\
98 & KOB-17 & 4 & 9.457 & 99 & WTN-50 & 0.3 \\
100 & WC-17 & 4 & 9.457 & 101 & WTN-51 & 0.3 \\
102 & TJ-17 & 4 & 9.457 & 103 & WTN-52 & 0.3 \\
104 & KOB-18 & 4 & 4.472 & 105 & WTN-53 & 0.3 \\
106 & WC-18 & 4 & 4.472 & 107 & WTN-54 & 0.3 \\
108 & TJ-18 & 4 & 4.472 & 109 & WTN-55 & 0.3 \\
110 & KOB-19 & 4 & 2.115 & 111 & WTN-56 & 0.3 \\
112 & WC-19 & 4 & 2.115 & 113 & WTN-57 & 0.3 \\
114 & TJ-19 & 4 & 2.115 & 115 & WTN-58 & 0.3 \\
116 & KOB-20 & 4 & 1 & 117 & WTN-59 & 0.3 \\
118 & WC-20 & 4 & 1 & 119 & WTN-60 & 0.3 \\
120 & TJ-20 & 4 & 1 & 121 & WTN-61 & 0.3 \\
\hline
\end{tabular}

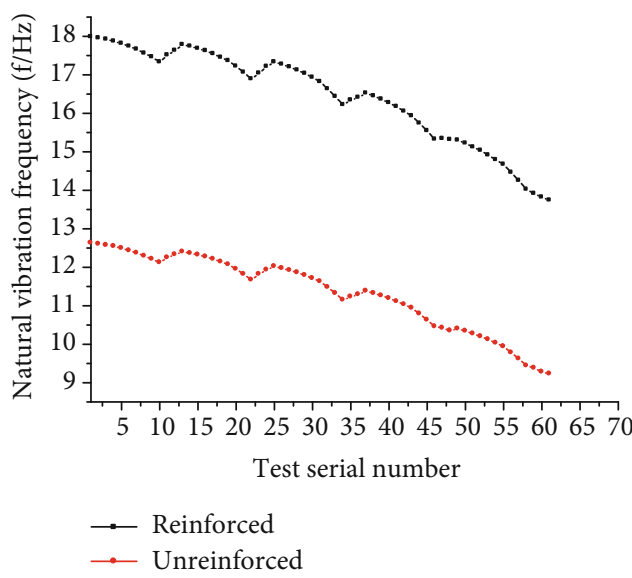

(a)

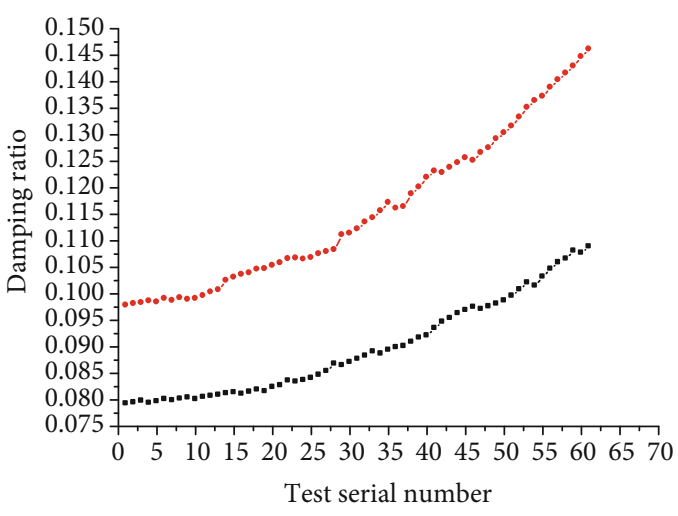

(b)

Figure 8: Variation curves of natural frequency and damping ratio with loading history. (a) Variation curve of natural frequency of embankment model with loading history (b) Variation curve of embankment model damping ratio with loading history.

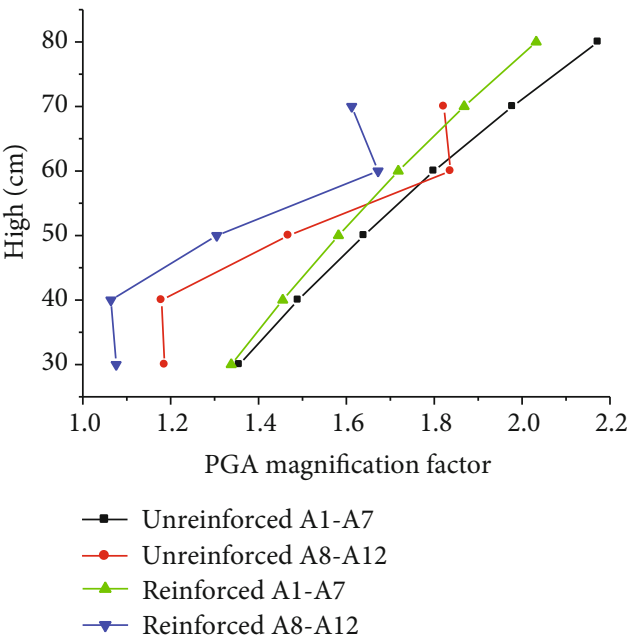

Figure 9: Comparison curve of PGA amplification factor under KOB-18 working condition.

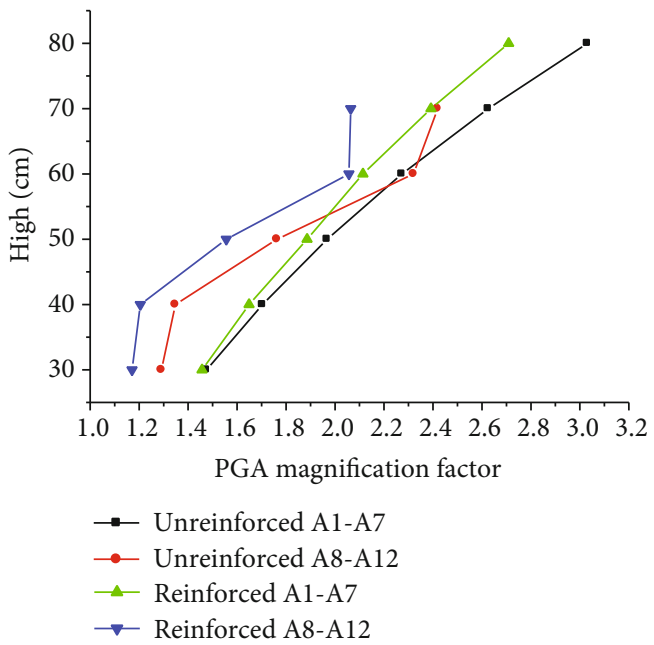

FIgURE 10: Comparison curve of PGA amplification factor under KOB-5 working condition. 


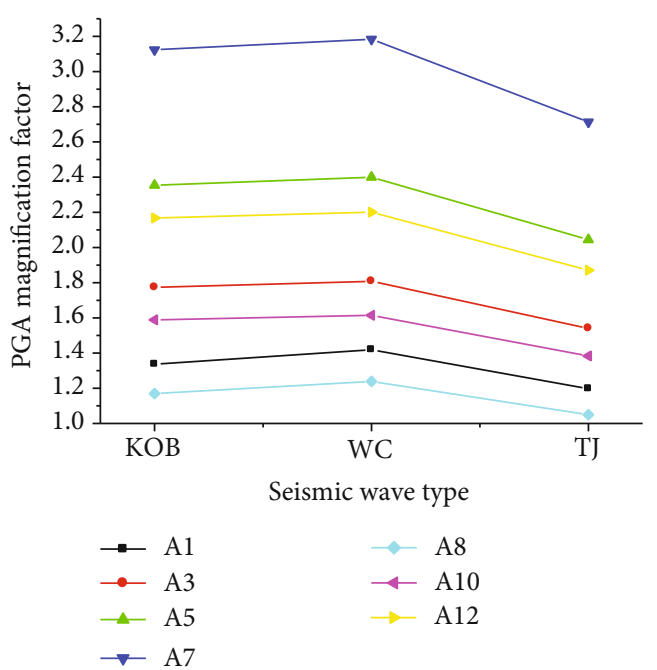

(a)

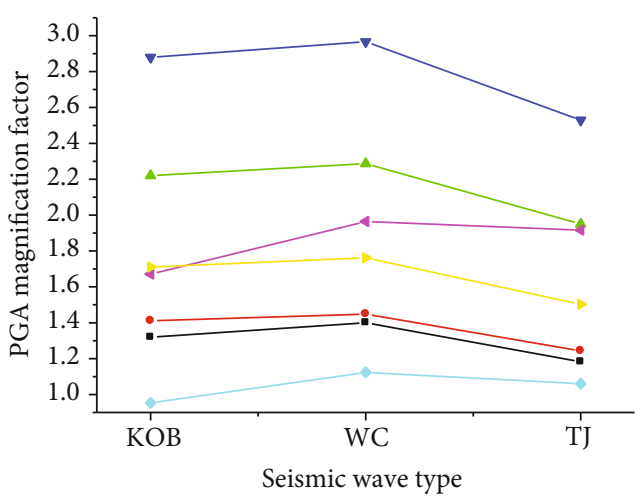

(b)

FIGURE 11: PGA amplification coefficients of measurement points on embankments under different types of seismic waves. (a) PGA amplification coefficients of measurement points on unreinforced embankments (b) PGA magnification coefficients of measurement points on reinforced embankments.

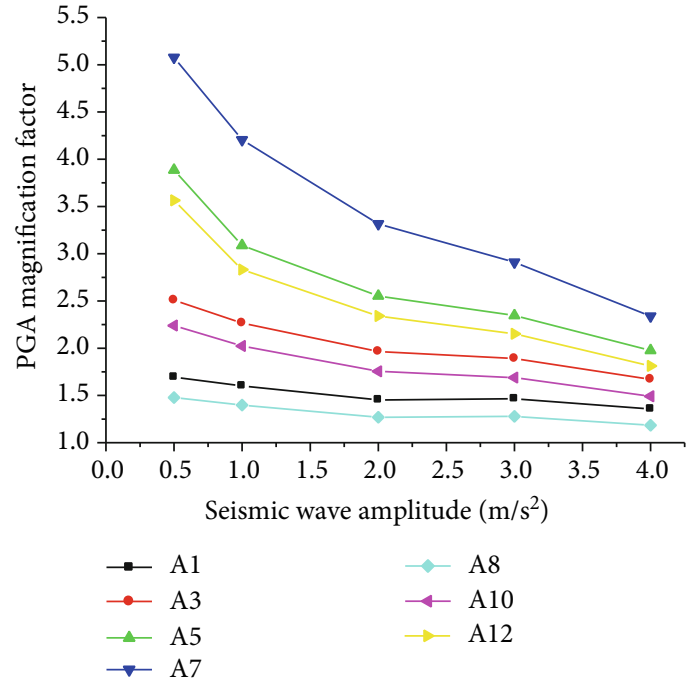

(a)

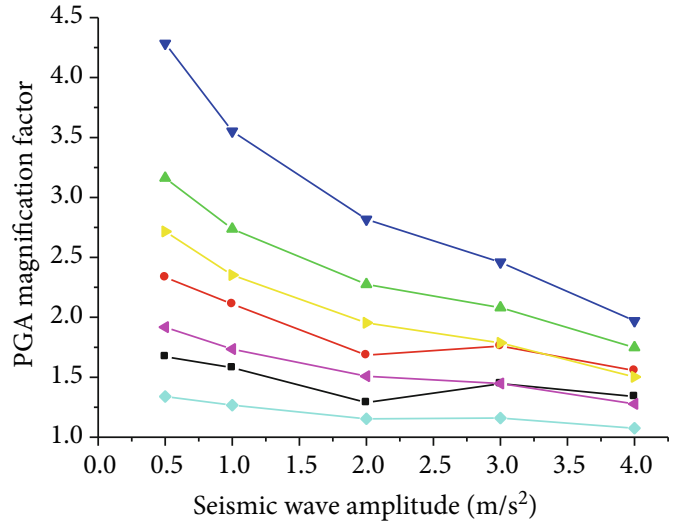

(b)

FIgURE 12: Changes in PGA amplification coefficient of measurement points on embankment with amplitude. (a) PGA amplification coefficient of measurement points on unreinforced embankment. (b) PGA amplification coefficient of measurement points on reinforced embankment.

the same height are less than those of the unreinforced embankment. The analysis of two types of embankment model slope body measuring points PGA amplification factor indicates that the lower and upper quarter height range of the slope body shows a small increase. The upper part even shows a decrease in a certain height range, and the middle part exhibits the fastest increase. Moreover, no increase is observed at the same height of the reinforced embankment. The PGA amplification factor of the A11 measurement point in the slope was greater than that of the slope A4; however, the reinforced embankment did not exhibit this phenomenon, indicating that the reinforcement exerted an inhibitory effect on the PGA amplification effect of the embankment, in particular, the internal slope.

Based on the test data, the influences of seismic wave type, seismic wave amplitude, and seismic wave frequency on the PGA amplification factor are discussed below.

(1) Influence of Seismic Wave Type. In order to discuss the impact of seismic wave types on the acceleration response of the two embankment models, the KOB-10, WC-10, and TJ-10 working conditions were selected for analysis. The amplitude for all the three seismic waves was $2 \mathrm{~m} \mathrm{~s}^{-2}$, and the time compression ratio was 4.472 . Figure 11 , respectively, 


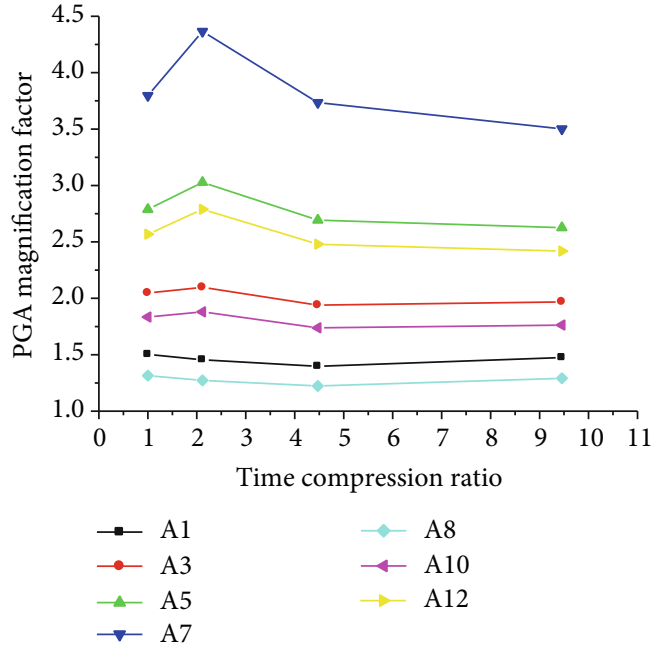

(a)

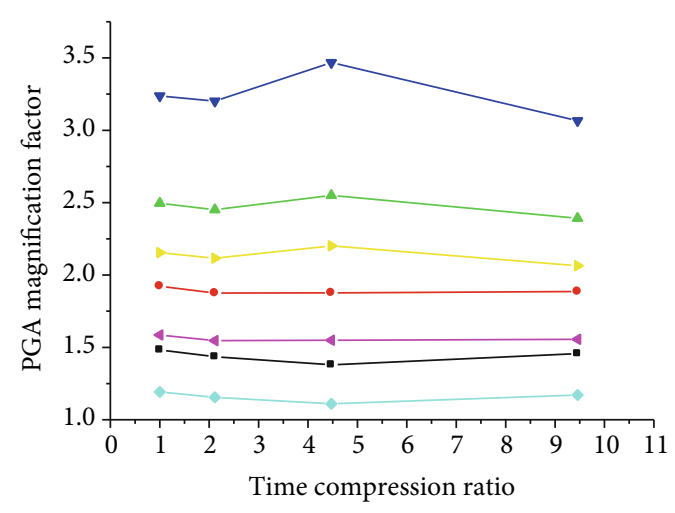

(b)

FIGURE 13: Variation curves of PGA amplification coefficients of measurement points on embankment with frequency. (a) Curve of PGA amplification coefficient at measuring point of unreinforced embankment (b) Curve of PGA amplification coefficient at measuring point of reinforced embankment.

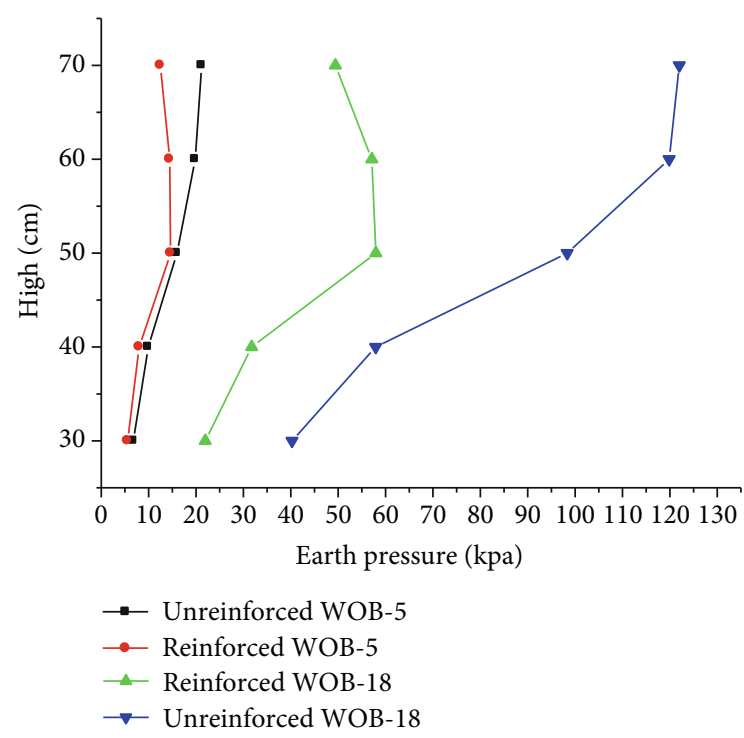

Figure 14: Peak earth pressure distribution of the two sets of embankment models.

shows the same amplitude and time compression ratio, the PGA amplification coefficients of two embankment slopes $\mathrm{A} 1, \mathrm{~A} 3, \mathrm{~A} 5, \mathrm{~A} 7$ and $\mathrm{A} 8, \mathrm{~A} 10$, and $\mathrm{A} 12$ on the slope of the slope.

The figure illustrates that at the same amplitude and time compression ratio, the PGA amplification factor of the embankment measurement point under the action of the WC wave is the largest, followed by that of the KOB wave, and that of the TJ wave is the smallest. Moreover, PGA amplification effects of other points exhibit the same rule as the given measuring points. It shows that when the types of seismic waves are different, the PGA amplification coefficients of the measurement points at the same location of the embankment are also different. Furthermore, the PGA amplification factor of reinforced embankments is significantly lower than that of unreinforced embankments.

(2) Influence of Seismic Wave Amplitude. In order to discuss the impact of seismic wave amplitude on the acceleration response of the two embankment models, the Wenchuan waves WC-4, WC-8, WC-12, WC-16, and WC-20 with different amplitude operating conditions were selected for analysis. Moreover, the above-mentioned operating conditions show the same time compression ratio and seismic wave type; however, the acting amplitude is $0.5,1,2,3$, and $4 \mathrm{~m} \mathrm{~s}^{-}$ ${ }^{2}$, respectively. Figure 12 shows the PGA amplification coefficients of the two embankment models and the variation curves of seismic wave amplitude.

The figure shows that the PGA amplification coefficients of the two embankment model measuring points generally decrease with the increase of the seismic wave amplitude, and the PGA amplification coefficient of the slope top A7 measuring point shows the largest change. The two embankment seismic wave amplitudes are $0.5 \mathrm{~m} \mathrm{~s}^{-2}$, and the PGA amplification factor of the A7 measuring point can reach 2.2 times that of the amplitude $4 \mathrm{~m} \mathrm{~s}^{-2}$. The influence of KOB seismic wave and TJ seismic wave amplitude on PGA amplification coefficient is similar to that of WC seismic wave.

(3) Seismic Wave Frequency. In order to discuss the influence of seismic wave frequency on the acceleration response of the two embankment models, the Hanshin waves KOB-5, KOB6 , KOB-7, and KOB-8 were selected for the analysis of different frequency conditions, and the seismic wave amplitude of this condition was $1 \mathrm{~m} \mathrm{~s}^{-2}$. The time compression ratios are 1 , $20^{1 / 4}, 20^{1 / 2}$, and $20^{3 / 4}$, respectively. Figure 13 , respectively, shows the PGA amplification coefficient of the two embankment measurement points versus frequency. 


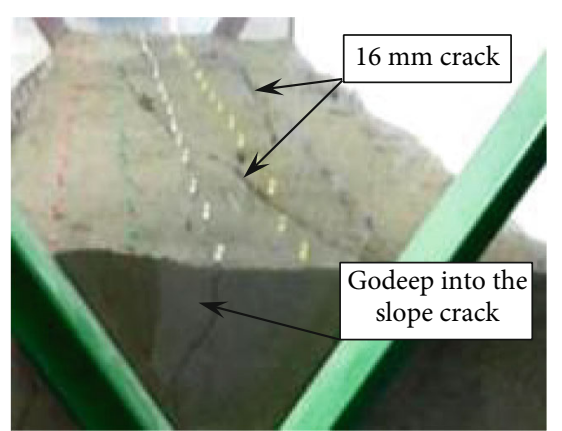

(a) Unreinforced embankment model top crack

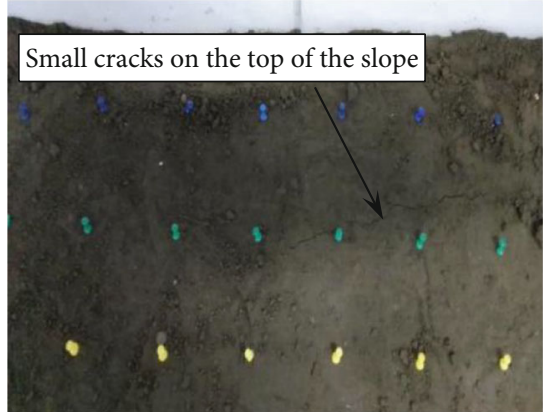

(c) Fine cracks on slope top of reinforced embankment model

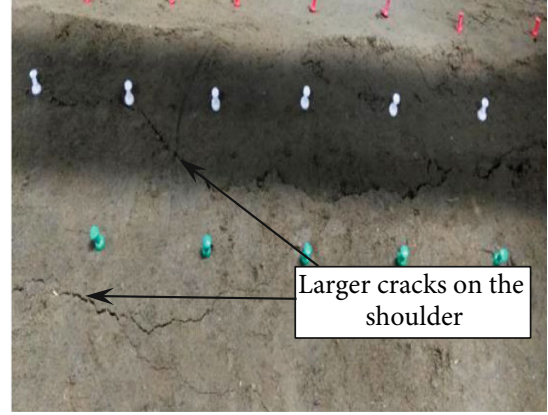

(b) Unreinforced road embankment model shoulder crack

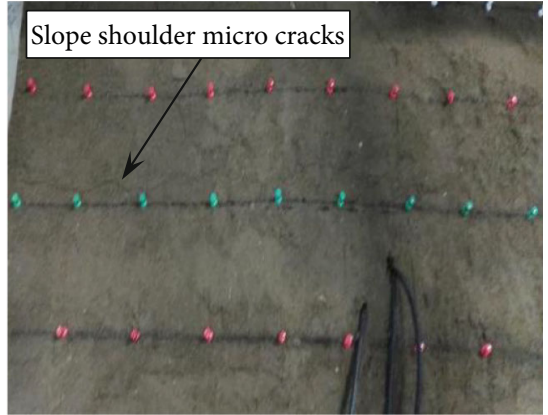

(d) Fine cracks on the slope of the reinforced embankment model

FIGURE 15: The damage and destruction patterns of the two embankment models.

The figure shows that the PGA amplification factor of the unreinforced embankment at the same input seismic wave frequency is greater than that of the reinforced embankment. Moreover, the PGA amplification factor of the two embankment measurement points changes with the input seismic wave frequency. The maximum value of the PGA amplification factor is on the upper part of the slope. For the measurement points, the maximum value of the PGA amplification factor of the measurement point of the unreinforced embankment appears in the range of the smaller time compression ratio, while the maximum value of the reinforced embankment is in the medium time compression ratio range. The influence of WC seismic wave and TJ seismic wave frequency on PGA amplification coefficient is similar to that of KOB seismic wave. It indicates that the resonance frequency of reinforced embankments is significantly higher than that of unreinforced embankments, and the frequency range of natural seismic action is closer to the natural frequency of unreinforced embankments. Therefore, reinforced embankments can effectively improve the seismic behavior of embankments.

4.2.2. Analysis of Measuring Point Dynamic Earth Pressure. The dynamic earth pressure in the embankment under the action of earthquake is the main controlling factor to the damage and destruction of the embankment. In order to discuss the change law of the dynamic earth pressure along the height of the two embankment models, the KOB-5 and KOB18 loading conditions were selected for analysis. The distribution curves of the peak dynamic earth pressure at the measuring point are shown in Figure 14.
The figure exhibits that the peak dynamic soil pressure at the measurement point of the unreinforced embankment at the same height is significantly greater than that of the reinforced embankment. For the KOB-5 and KOB-18 working conditions, the peak dynamic soil pressure at the Y5 measurement point of the unreinforced embankment is 1.7 times that of the reinforced embankment, respectively, and then 2.5 times. Clearly, the reinforcement can effectively reduce the peak dynamic earth pressure in the embankment. Moreover, the graph and curve reveal that reinforcement measures can effectively adjust the peak dynamic earth pressure distribution in the embankment, greatly reduce the dynamic earth pressure in the upper part of the embankment, and significantly improve the dynamic stability of the embankment.

4.3. Failure Characteristics of Embankment Model. During the test, the dynamic characteristics and dynamic response parameters of the embankment were collected and analyzed. At the same time, the deformation and crack failure characteristics of the embankment were observed and measured in detail. After the peak acceleration loading of $2 \mathrm{~m} \mathrm{~s}^{-2}$ was completed, no cracks were observed in the two embankment models. After the completion of the peak acceleration loading of $3 \mathrm{~m} \mathrm{~s}^{-2}$, fine cracks appeared on the upper and middle slopes of the two embankment models. When the peak acceleration of $4 \mathrm{~m} \mathrm{~s}^{-2}$ was loaded, the cracks in the unreinforced embankment model became wider. The cracks were mainly distributed in the middle, and the upper part of the embankment and the slope shoulder. The width of the larger cracks reached $16 \mathrm{~mm}$, and some cracks could be seen deep into the third part of the slope. The top of the embankment model 
subsided to $27 \mathrm{~mm}$, and the slope was convex. After the reinforced embankment model was loaded, only two small cracks appeared on the shoulder and top of the slope, and the slope top settlement was less than $5 \mathrm{~mm}$. The damage and destruction patterns of the two embankment models are shown in Figure 15.

\section{Conclusions}

Aiming at the seismic response of plastic geogrid-reinforced embankment, with Zhounan Expressway as the research engineering background, a comparative model test of plastic geogrid-reinforced embankment and unreinforced embankment was designed and further conducted, and the embankment model was tested in various earthquake scenarios. The dynamic characteristics and dynamic response under loading conditions were analyzed. The change laws of the embankment's natural frequency, damping ratio, acceleration at the measuring point, and dynamic soil pressure were analyzed, and the main influencing factors and damage characteristics of the embankment seismic response were discussed. Through the systematic analysis of the test data, the following conclusions can be obtained:

(1) The dynamic characteristics such as the initial natural frequency and damping ratio of the plasticreinforced embankment were found to be significantly better than those of the unreinforced embankment. The reinforcement led to the increase in the initial natural frequency of the embankment by $42.4 \%$, and the initial damping ratio decreased by $19.4 \%$. The reinforcement reduced the embankment natural frequency by $3.3 \%$ with the loading history, and the damping ratio decreased by $12.1 \%$ with the loading history

(2) Plastic reinforcement exhibited a good suppression effect on the PGA amplification effect of the embankment; in particular, the suppression effect on the interior of the slope was more significant than that on the slope. The type, amplitude, and frequency of seismic waves exhibited an important influence on the PGA amplification effect of the embankment

(3) Plastic reinforcement significantly reduced the peak dynamic earth pressure of the embankment at the same location. The analysis of representative working conditions and measurement point data indicated that the peak dynamic earth pressure could be reduced to $40 \%$ of the unreinforced embankment. Reinforcement could not only effectively reduce the peak dynamic earth pressure but also effectively adjust the peak dynamic earth pressure distribution in the embankment, greatly reduce the dynamic earth pressure in the upper part of the embankment, and significantly improve the dynamic stability of the embankment

(4) Reinforcement could effectively improve the antivibration damage performance of the embankment.
After loading with a peak acceleration of $3 \mathrm{~m} \mathrm{~s}^{-2}$, relatively small cracks appeared in the upper part of the slope of the two embankment models. However, when the peak acceleration of $4 \mathrm{~m} \mathrm{~s}^{-2}$ was loaded, the cracks of the unreinforced embankment model evolved into cracks, and the cracks were mainly distributed in the embankment. In the middle and upper part and the slope shoulder, the width of the larger cracks reached $16 \mathrm{~mm}$, and some cracks penetrated one-third of the height of the slope, and there was serious settlement at the top. The maximum settlement at the top of the embankment model was $27 \mathrm{~mm}$, and the slope was convex. However, the reinforced embankment model only showed two small cracks on the slope shoulder and top, and the slope top settlement was less than $5 \mathrm{~mm}$. Reinforcement can significantly improve the strong earthquake resistance of the embankment

\section{Data Availability}

The data are available and explained in this article; readers can access the data supporting the conclusions of this study.

\section{Disclosure}

I would like to declare on behalf of my coauthors that the work described is original research and has not been previously published.

\section{Conflicts of Interest}

The authors declare no conflict of interest. The manuscript is approved by all authors for publication.

\section{Acknowledgments}

This work was supported by the National Key Research \& Development plan of China (2016YFC0600901).

\section{References}

[1] J. Zhu, Geogrid Reinforcement of Soft Soil Subgrade Time Effect and Seismic Dynamic Response Analysis, Dalian Maritime University, 2017.

[2] L. Jinbei, Study on Seismic Performance of HighwaySubgrade, Beijing Jiaotong University, 2013.

[3] W. Jian, Y. Lingkan, and C. Qiang, "Research on failure mode of road embankment in Wenchuan great earthquake and deformation control of geogrid reinforcement," Chinese Journal of Rock Mechanics and Engineering, vol. 29, Supplement 1, pp. 3387-3394, 2010.

[4] Q. Yelin, P. Guo, J. Wang, W. Lu, S. Shengbiao, and Y. Wang, "A review of the dynamic response characteristics of fiber reinforced soil," Geotechnical Foundation, vol. 30, no. 6, pp. 705713,2016

[5] C. Jianzhou, L. Huabei, and F. Cheng, "Seismicresponse analysis of back-to-back mechanicallly stabilized earth(MSE) walls," Chinese Journal of Geotechnical Engineering, vol. 41, no. 5, pp. 918-926, 2019. 
[6] D. Lesniewska, "RES - a numerical program for reinforcedsoil slopes based on the rigid-plastic theoretical model," Geotextiles and Geomembranes, vol. 12, no. 5, pp. 435-439, 1993.

[7] K. Halder, D. Chakraborty, and S. K. Dash, "Bearing capacity of a strip footing situated on soil slope using a nonassociated flow rule in lower bound limit analysis," International Journal of Geotechnical Engineering, vol. 3, pp. 1-9, 2017.

[8] H. Nouri, A. Fakher, and C. J. F. P. Jones, "Evaluating the effects of the magnitude and amplification of pseudo-static acceleration on reinforced soil slopes and walls using the limit equilibrium horizontal slices method," Geotextiles and Geomembranes, vol. 26, no. 3, pp. 263-278, 2008.

[9] Y. L. Lin, W. M. Leng, G. L. Yang, L. Li, and J. S. Yang, "Seismic response of embankment slopes with different reinforcing measures in shaking table tests," Natural Hazards, vol. 76, no. 2, pp. 791-810, 2015.

[10] L. Lihua, R. Zengle, L. Guangxin et al., "Shaking table model testsfor composite reinforcedslopes," Journal of Southwest Jiaotong University, vol. 52, no. 3, pp. 496-504, 2017.

[11] H. Zhu, Y. Lingkan, C. Xiaolong, and X. Qin, "Seismic behaviors and design recommendations of ecological bag-reinforced retaining wall," Chinese Journal of Geotechnical Engineering, vol. 39, no. 2, pp. 319-326, 2017.

[12] T. Lu, Shaking Table Test Analysis of Dynamic Characteristics of Composite Gabion and Geogrid Reinforced Soil Retaining Wall, Institute of Disaster Prevention, 2019.

[13] J. Guanlu, P. Xu, and W. Zhimeng, "Study on reinforced soil retaining wall with composite panels by model test[J]," Railway Engineering, vol. 58, no. 1, pp. 118-120, 2018.

[14] N. Srilatha, G. Madhavi Latha, and C. G. Puttappa, "Effect of frequency on seismic response of reinforced soil slopes in shaking table tests," Geotextiles and Geomembranes, vol. 36, pp. 27-32, 2013.

[15] H. Bahadori, H. Motamedi, A. Hasheminezhad, and R. Motamed, "Shaking table tests on shallow foundations over geocomposite and geogrid-reinforced liquefiable soils," Soil Dynamics and Earthquake Engineering, vol. 128, p. 105896, 2020.

[16] A. Komak Panah, M. Yazdi, and A. Ghalandarzadeh, "Shaking table tests on soil retaining walls reinforced by polymeric strips," Geotextiles and Geomembranes, vol. 43, no. 2, pp. 148-161, 2015.

[17] J. Wartman, R. B. Seed, and J. D. Bray, "Shaking table modeling of seismically induced deformations in Slopes," Journal of Geotechnical and Geoenvironmental Engineering, vol. 131, no. 5, pp. 610-622, 2005.

[18] J. Koseki, R. J. Bathurst, E. Guler, J. Kuwano, and M. Maugeri, "Seismic stability of reinforced soil walls," in 8th International Conference on Geosynthetics, pp. 51-77, Yokohama, Japan, 2006.

[19] A. Edinçliler, G. Baykal, and A. Saygili, Seismic Behavior of Geogrid Reinforced Slagwall, American Institute of Physics, 2008.

[20] Z. Li, S. G. Liu, W. T. Ren, J. J. Fang, Q. H. Zhu, and Z. L. Dun, "Multiscale laboratory study and numerical analysis of waterweakening effect on shale," Advances in Materials Science and Engineering, vol. 2020, Article ID 5263431, 14 pages, 2020.

[21] T. Zhigang, Z. Chun, W. Yong, W. Jiamin, H. Manchao, and Z. Bo, "Research on stability of an open-pit mine dump with fiber optic monitoring," Geofluids, vol. 2018, Article ID 9631706, 20 pages, 2018.

[22] Y. Wang, B. Zhang, S. H. Gao, and C. H. Li, "Investigation on the effect of freeze-thaw on fracture mode classification in marble subjected to multi-level cyclic loads," Theoretical and Applied Fracture Mechanics, vol. 111, article 102847, 2021.

[23] Z. G. Tao, C. Zhu, M. C. He, and M. Karakus, "A physical modeling-based study on the control mechanisms of Negative Poisson's ratio anchor cable on the stratified toppling deformation of anti- inclined slopes," International Journal of Rock Mechanics and Mining Sciences, vol. 138, article 104632, 2021.

[24] C. Zhu, Z. Yan, Y. Lin, F. Xiong, and Z. Tao, "Design and application of a monitoring system for a deep railway foundation pit project," IEEE Access, vol. 7, pp. 107591-107601, 2019.

[25] Q.-X. Meng, W.-Y. Xu, H.-L. Wang, X.-Y. Zhuang, W.-C. Xie, and T. Rabczuk, "DigiSim - an open source software package for heterogeneous material modeling based on digital image processing," Advances in Engineering Software, vol. 148, p. $102836,2020$. 